\title{
INHOMOGENEOUS LIPSCHITZ SPACES ASSOCIATED WITH FLAG SINGULAR INTEGRALS AND THEIR APPLICATIONS
}

\author{
ShaOyong He* AND Jiecheng Chen
}

Abstract. This note is motivated by Müller, Ricci and Stein's work in [29]. We introduce a new class of inhomogeneous Lipschitz spaces associated with flag singular integrals and characterize these spaces via the Littlewood-Paley theory. We prove that inhomogeneous flag singular integral operators are bounded on these Lipschitz spaces.

Mathematics subject classification (2020): 42B35, 42B25, 42B20, 46E30. theory.

Keywords and phrases: Flag singular integrals, inhomogeneous Lipschitz spaces, Littlewood-Paley

\section{REFERENCES}

[1] S.-Y. A. Chang And R. FefFerman, A continuous version of duality of $H^{1}$ with BMO on the bidisc, Ann. of Math., 112, 1 (1980), 179-201.

[2] S.-Y. A. Chang And R. FefFerman, The Calderón-Zygmund decomposition on product domains, Amer. J. Math., 104, 3 (1982), 455-468.

[3] S.-Y. A. ChANG AND R. FefFerman, Some recent developments in Fourier analysis and $H^{p}$ theory on product domains, Bull. Amer. Math. Soc., 12, 1 (1985), 1-43.

[4] D.-C. Chang, Y. Han And X. Wu, Relations between product and flag Hardy Spaces, J. Geom. Anal., 31, 7 (2021), 382-395.

[5] J. CHEEGER, Differentiability of Lipschitz functions on metric measure spaces, Geom. Funct. Anal., 9, 3 (1999), 428-517.

[6] X. Duong, J. Li, Y. Ou, J. Pipher And B. Wick, Commutators of multiparameter flag singular integrals and applications, Anal. PDE, 12, 5 (2019), 1325-1355.

[7] R. FeFFerman, Singular integrals on product $H^{p}$ spaces, Rev. Mat. Iberoam., 1, 2 (1985), 25-31.

[8] R. FefFerman, Calderón-Zygmund theory for product domains: $H^{p}$ spaces, Proc. Nat. Acad. Sci. U.S.A., 83, 4 (1986), 840-843.

[9] R. FefFerman, Harmonic analysis on product spaces, Ann. of Math., 126, 1 (1987), 109-130.

[10] R. FEFFERMAN AND J. PIPHER, Multiparameter operators and sharp weighted inequalities, Amer. J. Math., 119, 2 (1997), 337-369.

[11] R. FefFerman And E. M. Stein, Singular integrals on product spaces, Adv. Math., 45, 2 (1982), $117-143$.

[12] M. FraZier And B. Jawerth, A discrete transform and decomposition of distribution, J. Funct. Anal., 93, 1 (1990), 34-170.

[13] M. FrAZIER, B. JAWERTH AND G. WeISs, Littlewood-Paley theory and the study of function spaces, CBMS Regional Conference Series in Mathematics, 79, American Mathematical Society, Providence, R.I., 1991, viii+132 pp.

[14] D. Goldberg, A local version of real Hardy spaces, Duke Math. J., 46, 1 (1979), 27-42.

[15] R. Gundy And E. M. Stein, $H^{p}$ theory for the poly-disk, Proc. Nat. Acad. Sci., 76, 3 (1979), $1026-1029$.

[16] Y. HAN AND Y. HAN, Boundedness of composition operators associated with mixed homogeneities on Lipschitz spaces, Math. Res. Lett., 23, 5 (2016), 1387-1403.

[17] Y. HAN, Y. HAN, J. Li AND C. TAN, Marcinkiewicz multipliers and Lipschitz Spaces on Heisenberg groups, Canad. J. Math., 71, 3 (2019), 607-627. 